\title{
EXPERIMENTAL INVESTIGATION OF PRECAST WALL JOINTS BY USING SIFCON
}

\author{
K.Sakthi Prasanth ${ }^{1}$, A.Sumil Kumaran ${ }^{2}$, S.Parthibavelan ${ }^{3}$, S.Arunkumar ${ }^{4}$ \\ ${ }^{1}$ Post Graduate Student, Structural Engineering, KPR Institute of Engineering and Technology, Tamilnadu, India \\ ${ }^{2}$ Post Graduate Student, Structural Engineering, Erode Builder Educational Trust's Group of Institutions, Tamilnadu, \\ India \\ ${ }^{3}$ Post Graduate Student, Structural Engineering, PSNA Engineering and Technology, Tamilnadu, India \\ ${ }^{4}$ Post Graduate Student, Structural Engineering, Sona college of Technology, Tamilnadu, India
}

\begin{abstract}
In India, the construction field streams towards the hike with the advent of new innovative technologies. The increase in the quantity of construction seeks the superior quality from the researchers in terms of effective methodologies which reduce the requirement of manpower and material with increased efficiency and pace of construction. One of the most promising solutions for this issue suggested by the researchers is the precast construction. Precast construction entirely restructures the conventional construction process to improve the quality and pace of the construction. The predicaments with precast construction are shrinkage of filling material between the wall which leads to crack formation and also cause leakage of water. The occurrence of shrinkage is initiated and leaded by the compacting or filling problem in filling materials up to ground level due to the use of coarse aggregate and the usage of non flexible and improper bonding of sealant in the wall joints. In order to reduce these structural problems, we investigated the method of SIFCON (slurry infiltrated fibre concrete) with varies mix proportion 1: 1, 1:1.5 and 1:2 with the replacement of coarse aggregate by perlite. The sealant we used is poly sulphide sealant and the watercement ratio of the filling material varies between 0.3 and 0.4. Even though the conventional practical way of using fibres in SIFCON is limited up to $12 \%$, we investigated the usage of fibres up to $20 \%$ in this experiment. The results obtained from the experiment shows that the filling material with the cement mortar ratio of 1:1.5 with 5\% glass fibre applied in the method of Slurry Infiltrated Fibre Concrete successfully arrests the leakage of water between the wall joints.
\end{abstract}

Keywords: Glass Fibre, PERLITE, SIFCON (Slurry Infiltrated Fibre Concrete), Poly Sulphide. $* * *$

\section{INTRODUCTION}

Indian infrastructural requirements pave the path to the arrival of most prompt technologies in the Indian construction industry. Those technologies should satisfy the necessities of the construction industry both in terms of quantity and quality. The researchers are in the position to create new technologies and to propagate their methodologies to regulate the above mentioned issues.

\subsection{Precast Construction}

Precast construction is a boon to the construction industry which can be differentiated from the conventional methods of construction as the elevator differentiated from the conventional staircases i.e the main differentiation is the speed and the perfection with lesser effort in construction.

The design part seems to be the same for both conventional cast insitu and the precast construction, except some factors. The real variation lies in the construction part of both the types. Unlike the conventional construction, in this construction the structural elements are casted away from the location where they are allocated to stand throughout its life time. Most difficult and even impossible shapes and architectural finishes in conventional way of construction can also be achievable in precast construction.

Like the union of layers forms the onion, the union of various individual structural elements such as beams, columns, slabs and walls forms the structure in precast construction. Those structural elements are fabricated off site and transported to assemble it on the site. While designing the elements the loads such as the erection and handling loads are added to the conventional loads such as dead, live, wind, snow and seismic loads as per the codal recommendation. Precast concrete usually is either ordinary reinforced concrete or prestressed reinforced concrete. Prestressing gives advantages of slender cross-section and steel requirements (reduced weight). However, prestressing needs additional equipments, abutments, manpower, economy etc.

Precast is also called as prefabrication which can be done both onsite and offsite according to the need and necessity of the situation. Basically the offsite is more popular and more preferable when compared to the onsite construction in case of precast or prefabrication. The offsite precast construction of structural element is preferred because of its quality made in sophisticated environment and accuracy in dimensions. 
However the transportation of the elements from the factory to the site is also an important factor to be considered in precast construction. Precast increases the pace of construction by reducing the time of construction such as curing of elements on site, forming and removing of scaffolding onsite.

The most familiar precast element which is widely used and available in India is the railway sleepers. The railway sleepers are not only precast but also prestressed (Post tensioned or pretensioned). The prefabrication can also be done on transportation and the method is called as mobile prefabrication. The precast elements can be made in several sizes and shapes for various purposes such as agricultural purpose (bunker silos), Bridges and building (Beams, columns, piers), Retaining walls, water storage and septic tanks, Culverts and modular pavements for roadways etc...

\subsection{Large Panels System}

The "large-panel system" refers to multistory structures composed of large wall and floor concrete panels connected in the vertical and horizontal directions so that the wall panels enclose appropriate spaces for the rooms within a building.

- Both vertical and horizontal panels resist gravity load and Wall panels are usually one story high.

- Horizontal floor and roof panels span either as one-way or two-way slabs.

- When properly joined together, these horizontal elements act as diaphragms that transfer the lateral loads to the walls.

\section{Cross-wall system}

- Cross wall system is one in which the main walls that resist gravity and lateral loads are placed in the short direction of the building.

- Cross-wall is a generic method of building construction, which the main walls that resist gravity and lateral loads are placed in the short direction of the building.

\section{Long wall system}

- In long wall system the walls resisting gravity and lateral loads are placed in the longitudinal direction.

- Widely used in industrial building and go-down structures.

\subsection{Advantages of Precast Construction}

- Precast elements are Self-supporting ready-made components are use and therefore there is no need for formwork, shuttering and scaffolding is greatly reduced.

- Construction time is reduced and buildings are completed sooner.

- On-site congestion is minimized in prefabrication.

- Quality control can be easily achieved.
- Prefabrication can be located where skilled labour is more readily available and costs of labour, power, materials, space and overheads are lower.

- Construction time is minimized during bad weather or hazardous environments.

- Less waste may

\subsection{Disadvantages of Precast Construction}

- Concrete panels or steel and glass panels are carefully handling.

- Attention has to be paid to the strength and corrosionresistance of structural elements.

- Similarly, leaks can form at joints in prefabricated components.

- Transportation costs may be higher.

- Large prefabricated sections require heavy-duty cranes.

- Precision measurement and handling to place in position.

\section{MATERIALS USED}

- Glass fibre

- Perlite

- Cement

- Sand

- Water

- Polysulphide sealant.

\subsection{Glass Fibre}

Commercially available glass fibers of aspect ratio between 1- 1.5 are collected and it was tested for chemical Composition. It has $\mathrm{SiO} 2$ (63.3\%), $\mathrm{Al} 2 \mathrm{O} 3$ (23.7\%), $\mathrm{CaO}$ (0.01 \%), B2O3 (0.01\%), $\mathrm{MgO}(10.6 \%), \mathrm{Na} 2 \mathrm{O}(0.21$ $\%), \mathrm{BaO}(0.2 \%), \mathrm{FeO}(0.21 \%)$ and Others $(0.03 \%)$.

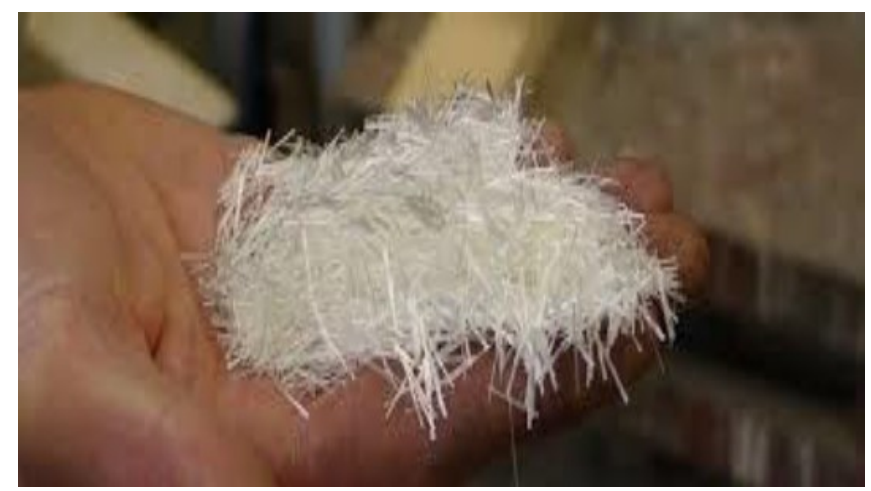

Fig-1: Glass fibre

\subsection{Perlite}

Perlite is an amorphous volcanic glass formed by the hydration of obsidian. It occurs naturally and that has relatively high water content,. The addition of Perlite gives smooth finishes to concrete that offers up to 20 times more thermal insulation than ordinary concrete. It also increases the density and compressive strength of concrete. commercially available Perlite was collected and tested for chemical Composition. The chemical composition was given in the following table. 


\subsubsection{Chemical Composition of Perlite:}

\begin{tabular}{|l|c|}
\hline Chemicals & $\begin{array}{c}\text { Composition } \\
\text { (\%) }\end{array}$ \\
\hline Silicon dioxide & 73 \\
\hline Aluminium oxide & 13 \\
\hline Sodium oxide & 3 \\
\hline Potassium oxide & 5 \\
\hline Iron oxide & 1.0 \\
\hline Magnesium oxide & 0.5 \\
\hline Calcium oxide & 0.5 \\
\hline $\begin{array}{l}\text { Loss on ignition } \\
\text { (chemical /combined } \\
\text { water) }\end{array}$ & 4 \\
\hline
\end{tabular}

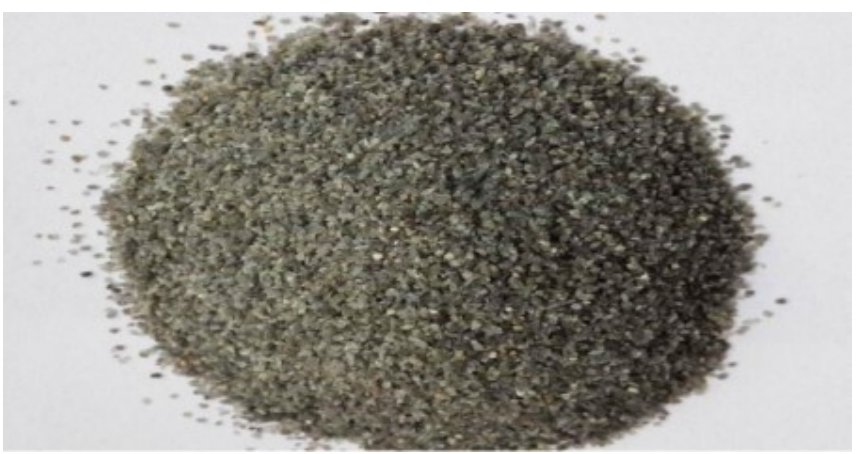

Fig-2: Perlite

\subsection{Polysulphide Sealant}

Polysulphide sealants are made with organic polysulfides, polymers with chains alternating sulfur and hydrocarbons.

Commercially available Polysulphide Sealant is very useful as sealants for joints that need to withstand prolonged immersion in liquids. It has excellent resistance to oil, water, sewage and temperature. They exhibit minimal shrinkage and good durability; It has wide applications include swimming pools, fountains, cooling towers, fuel and chemical storage tanks, wastewater treatment and petrochemical plants.

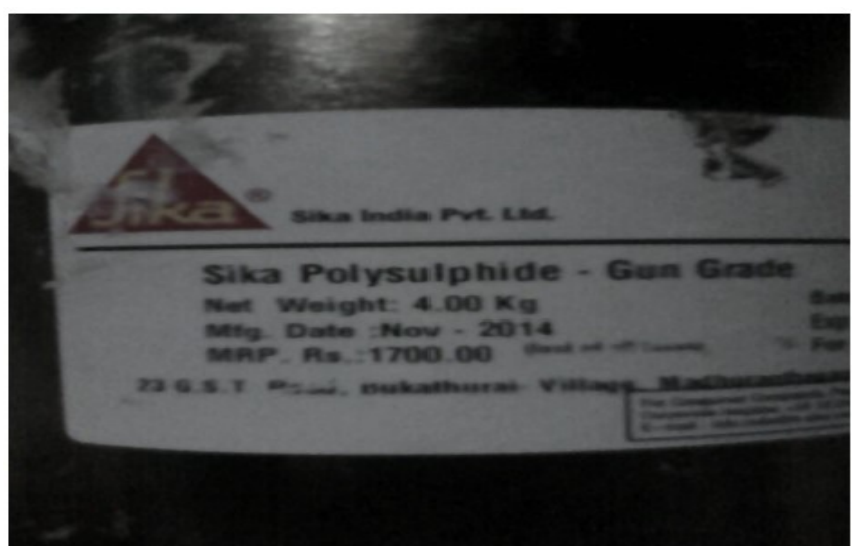

Fig-3: Polysulphide Sealant

\subsection{Cement}

Ordinary Portland Cement (OPC) IS: 8112-1989 was used. It has specific gravity of 3.2.

\subsection{River Sand}

Natural coarse river sandconforming toIS: $383-1970[6]$ was used. It has specific gravity of 2.7 and fineness modulus 3.17 .

\subsection{Coarse Aggregate}

Naturally available crushed coarse aggregate conforming to Indian Standard was used. It has specific gravity of 2.8 and fineness modulus 7.32.

\section{TRAIL AND ERROR METHOD}

\subsection{Method 1}

Using a method of SIFCON (Slurry Infiltrated Fibre CONcrete)

\subsubsection{SIFCON}

Slurry-Infiltrated Fibrous Concrete (SIFCON) is a special type of fibre concrete. It is recently developed in the field of FRC.

SIFCON has been used successfully for refractory applications, pavement overlays, and structures subjected to blast and dynamic loading. Because of its highly ductile behavior and far superior impact resistance, the composite has excellent potential for structural applications in which accidental or abnormal loads such as blasts are encountered during service. However, the composite was developed only recently and only limited data are available on its behaviour under different types of loading.

SIFCON has excellent potential for application in high ductility and resistance to impact. It also has superior mechanical properties such as shear, compressive, tensile and also flexural strength.

SIFCON is obtained by the fabrication method. In this method the steel fibres are placed in the pre prepared mould and poured the slurry like cement paste and therefore forming the required material shape. Due to the fabrication and moulding method it contains very high amount of steel fibres.

\subsection{Method 2}

Replacement of coarse aggregate with PERILITE.

\subsection{Method 3}

Use of flexible sealant. (POLY SULPHIDE). The flexible sealant is added along with the prepared SIFCON (Slurry Infiltrated Fibre CONcrete).

\section{WALL PANEL DETAILS}

\subsection{Precast Panels}

The wall panels are designed in the ratio of M40 with the hook for lifting purpose and also with the interlocking connection system. The size of panels designed for our project was $600 \times 600 \mathrm{~mm}$ and the thickness about $140 \mathrm{~mm}$. The groove about the thickness of $100 \mathrm{~mm}$ for pouring of concrete. Each panels is of weight up to $150 \mathrm{~kg}$. 


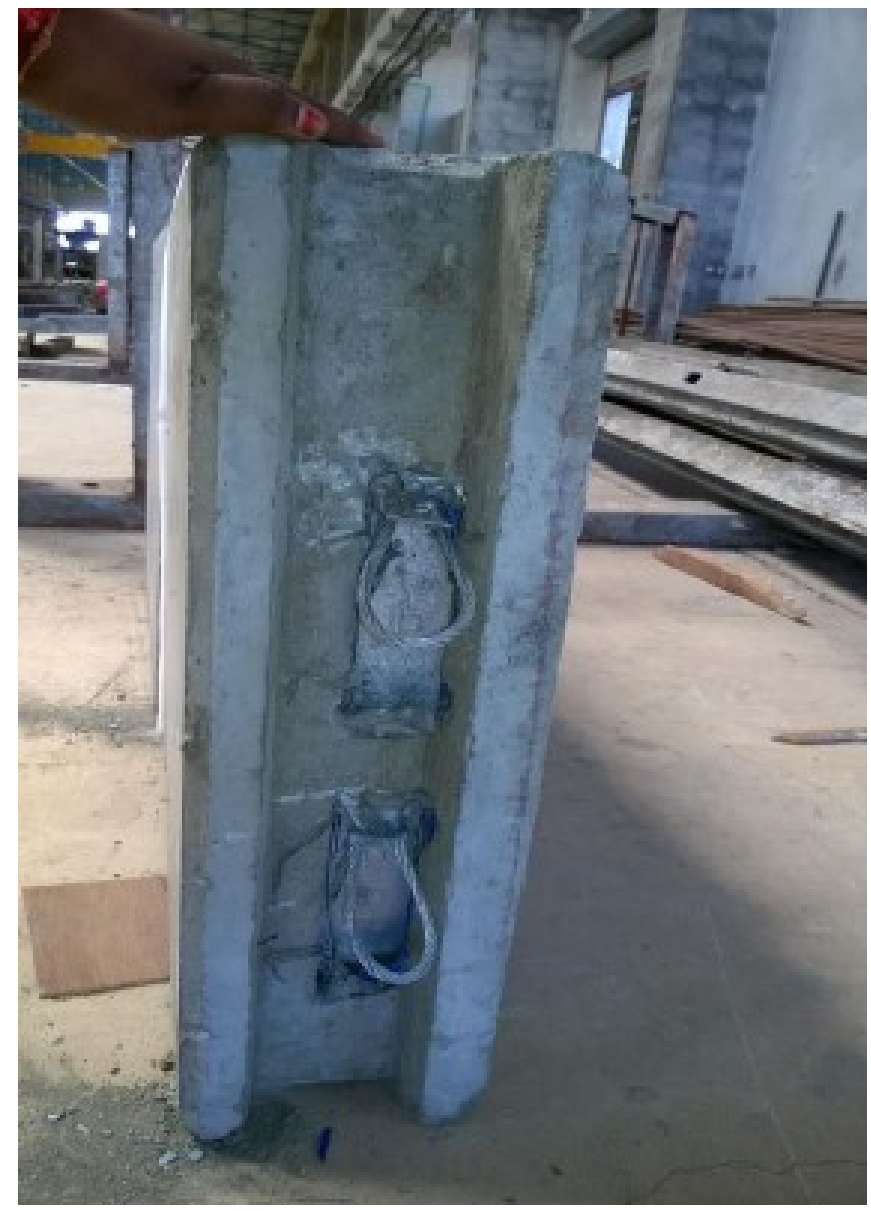

Fig-4: Lop Box

The gap between the two panels is about $30 \mathrm{~mm}$ and this gap is covered by the material of backer rod. Backer rod is the material which is used to maintain the pouring concrete within the joints, this material looks like a thermacoal. After setting of concrete the backer rod will be removed. The steel rod of $16 \mathrm{~mm}$ diameter inserted between the interlocking arrangements of two wall panels.

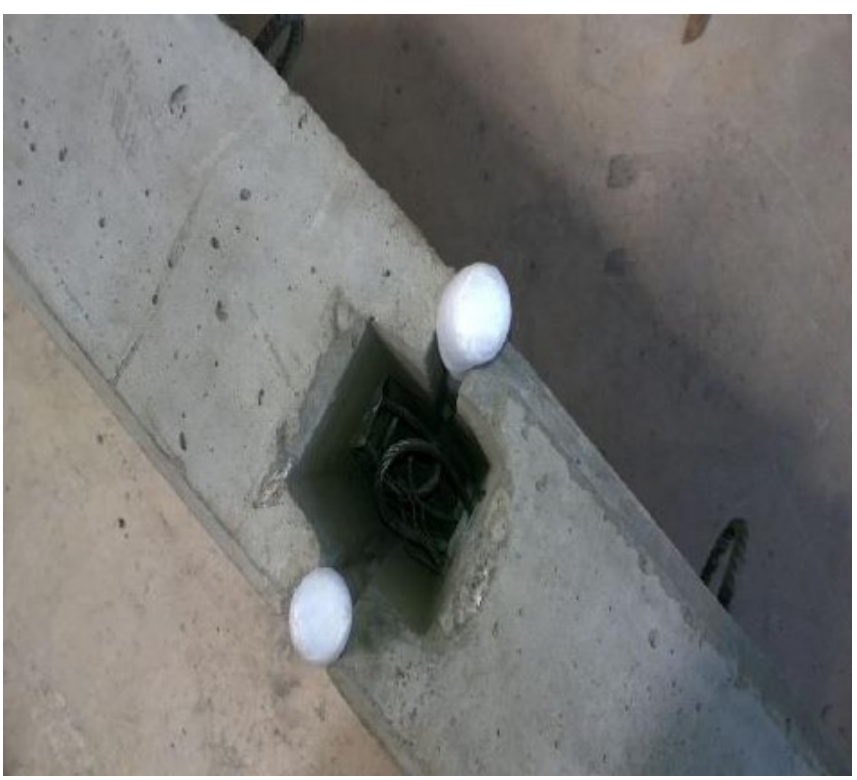

Fig-5: Panel Arrangement

\section{TEST PROCEDURE}

\subsection{Trial 1}

The cement slurry is prepared in the mix ratio of $1: 1.5$ (cement: sand) along with the mix $5 \%$ of glass fibre is added. The water cement ratio is to be maintained as 0.40 .

Initially the slurry was prepared with the mix ratio $1: 1.5$. Then the mix was filled along with the glass fibre in the gap between the wall joints. Then it was allowed for 24 hours to attain its strength by curing. The sample was maintained at normal temperature. Finally water leakage was checked out by stagnating the water for 24 hours and the water level was checked at consecutive intervals.

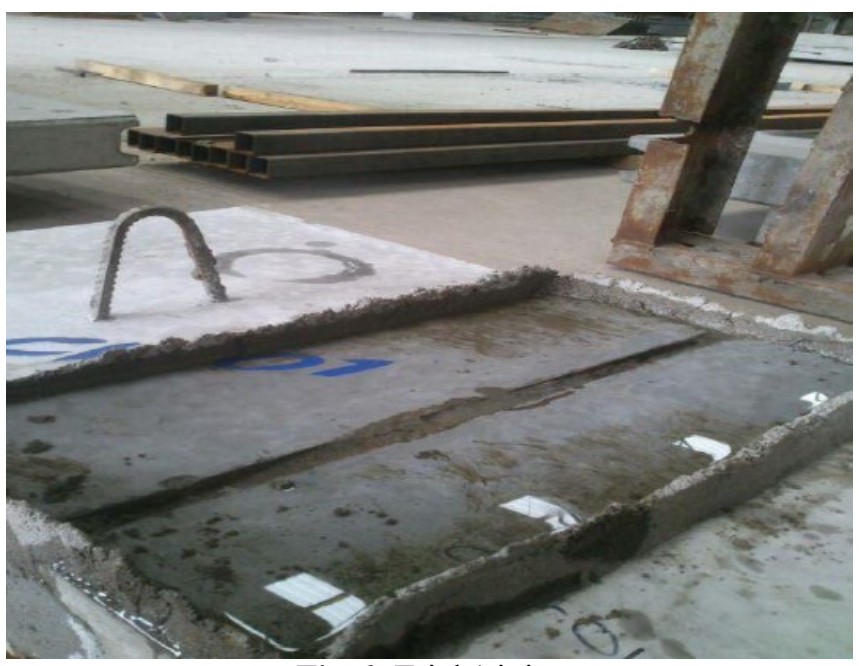

Fig-6: Trial 1 joint

\subsection{Trial 2}

The cement slurry is prepared in the mix ratio of $1: 1.5$ (cement: sand) along with the mix $8 \%$ of glass fibre is added. The water cement ratio is to be maintained as 0.40 . Initially the slurry was prepared with the mix ratio $1: 1.5$. Then the mix was filled along with the glass fibre $(8 \%)$ in the gap between the wall joints. Then it was allowed for 24 hours to attain its strength by curing. The sample was maintained at normal temperature. Finally water leakage was checked out by stagnating the water for 24 hours and the water level was checked at consecutive intervals.

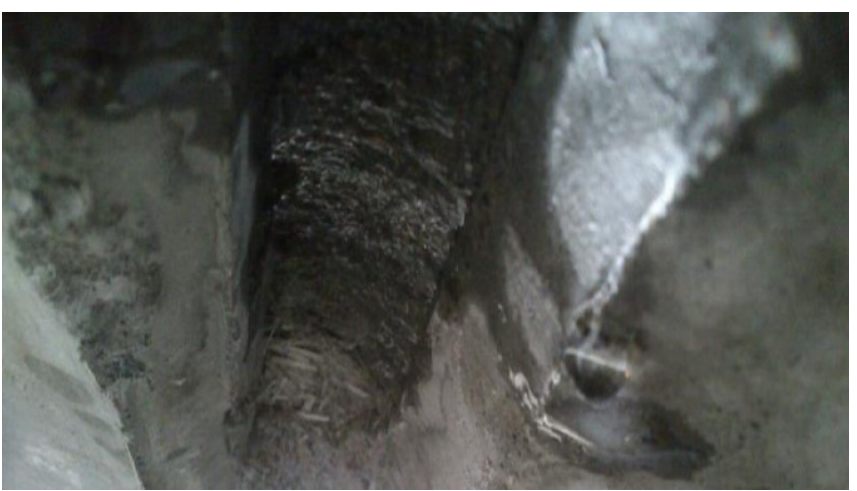

Fig-7: Trial 2 joint 


\subsection{Trial 3}

The cement slurry is prepared in the mix ratio of $1: 2$ (cement: sand) along with the mix $5 \%$ of glass fibre is added. The water cement ratio is to be maintained as 0.40 . Initially the slurry was prepared with the mix ratio $1: 2$. Then the mix was filled along with the glass fibre $(5 \%)$ in the gap between the wall joints. Then it was allowed for 24 hours to attain its strength by curing. The sample was maintained at normal temperature. Finally water leakage was checked out by stagnating the water for 24 hours and the water level was checked at consecutive intervals.

\subsection{Trial 4}

In this trail Method the coarse aggregate is replaced by perlite in the mix ratio of $1.45: 2.26: 3.8$. The water cement ratio is maintained as 0.40 .

In this trial, coarse aggregate was completely replaced by perlite. Concrete mix was prepared as per the standard mix design. Then the mix was filled in the gap between the wall joints. Then it was allowed for 24 hours to attain its strength by curing. The sample was maintained at normal temperature. Finally water leakage was checked out by stagnating the water for 24 hours and the water level was checked at consecutive intervals.

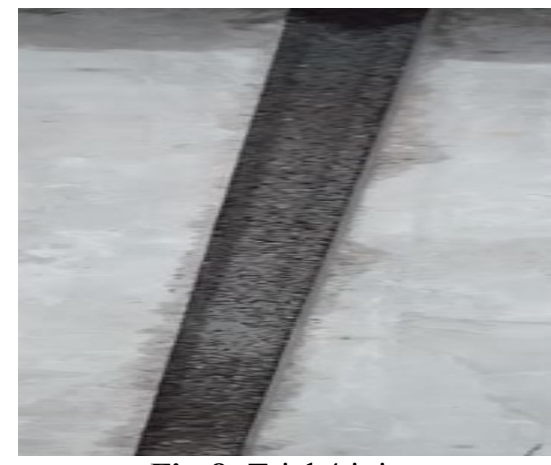

Fig-8: Trial 4 joint

\subsection{Trial 5}

In this trail Method the sealant is prepared as per specifications. Then it is applied between the joints. Then the joint was made dry for 24 hours. Water leakage was checked out by stagnating the water for 24 hours. The water level was checked at consecutive intervals.

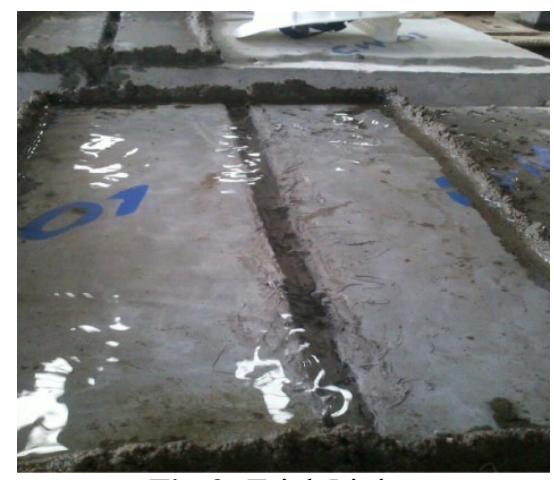

Fig-9: Trial 5 joint

\section{RESULTS OBSERVED}

From the above Trial and Error methods the following results are obtained.

- As the result of trial 1 , the water leakage was completely eliminated.

- In trial 2, visible cracks are found, as the sample was disturbed slightly. So, there was leakage of water.

- Trial 3 ended in failure, because there was water leakage.

- From the trail 4, there was leakage of water due to improper compaction.

- From the trail 5 it is noted that there is no water leakage by using Poly Sulphide Sealant.

And hence the mould is prepared to determine the hardened test of the SIFCON.

\subsection{Compression Test}

The compression test was conducted as per IS 516-1959. The specimens were kept in stream curing for 1 day and tested in dry condition.

\section{Procedure}

1. The prepared specimen of size $10 \times 10 \mathrm{~cm}$ is placed in centre of loading area in compression testing machine.

2. Down the piston just above the top of the concrete. Using lever arm applying the load gradually.

3. Now turn the pressure valve in clockwise position to lock so that compressive strength value gets initiated.

4. Initially $40 \mathrm{KN}$ and gradually increasing the load until the specimen fails and then turn the valve to move the piston to upward direction.

5. Take the specimen then the compressive strength value, scale and maximum load is noted.

Table-1: Comparison between Normal Mortar and Cube with Glass Fibre

\begin{tabular}{|l|l|l|l|}
\hline S.NO & SPECIMEN & $\begin{array}{l}\text { NORMAL } \\
\text { MORTAR } \\
\left.\text { CUBE (N/mm } \mathbf{m}^{2}\right)\end{array}$ & $\begin{array}{l}\text { CUBE } \\
\text { WITH } \\
\text { GLASS } \\
\text { FIBRE } \\
\text { (N/mm }^{2} \text { ) }\end{array}$ \\
\hline 1 & SAMPLE 1 & 42.457 & 44.647 \\
\hline 2 & SAMPLE 2 & 44.756 & 47.247 \\
\hline 3 & SAMPLE 3 & 43.281 & 45.612 \\
\hline
\end{tabular}

\section{CONCLUSION}

In order to reduce the structural problems such as cracking on concrete, leakage etc., the following trial and error methods are used. SIFCON (slurry infiltrated fibre concrete) with varies mix proportion 1: $1,1: 1.5$ and $1: 2$ and also subsequently use the poly sulphide sealant, replacement of coarse aggregate with PERILITE. The water-cement ratio varies between 0.3 and 0.4 . The percentage of fibres by volume can changes from 4 to $20 \%$.

- As the result of trial 1 , the water leakage was completely eliminated. 
- In trial 2, visible cracks are found, as the sample was disturbed slightly. So, there was leakage of water.

- Trial 3 ended in failure, because there was water leakage.

- From the trail 4, there was leakage of water due to improper compaction.

- From the trail 5 it is noted that there is no water leakage by using Poly Sulphide Sealant.

Finally the successful ratio obtained is 1:1.5 cement mortar using $5 \%$ glass fibre in the method of Slurry Infiltrated Fibre Concrete and also arrest leakage of water between the wall joints by using Poly Sulphide.

\section{REFERENCES}

[1]. B. Schneider, R. Mondragon, "Design and construction techniques for SIFCON" New Mexico Engineering Research Institute University of New Mexico I I Albuquerque, NM 87131.

[2]. Clay J. NAITO and Liling CAO, "Precast diaphragm panel joint connector performance"

[3]. G .Z.Zhang, Z. K. Fan, Y. W. Quan, Q. M. Chen, The preparation and physical properties of polysulfide-based elastomers through one-pot thiolene click reaction.

[4]. Hari Nurjamana, "Application of Precast System Buildings with Using Connection of Unbonded Post-tension and Local Dissipater Device" Pangeran Antasari 23, Jakarta 2150, Indonesia.

[5]. Kuldeep Dagar, "Slurry Infiltrated Fibrous Concrete (SIFCON)" Mewar University Chittorgarh, Rajasthan.

[6]. Mustaqqim Abdul Rahim, "Flexural Behaviour Of High Performance Slurry Infiltrated Fibre Reinforced Concerete With Different Curing Method"

[7]. Ramin Vaghe, "Evaluate Performance of Precast Concrete wall to wall Connection", University Putra Malaysia, Serdang, Malaysia.

[8]. V. S. Parameswaran, "Studies on Slurry-Infiltrated Fibrous Concrete (SIFCON)"

[9]. M. H. Irfan. "Polysulphides in the construction industry", Chemistry and Technology of Thermosetting Polymers in Construction Applications", 1998.

[10]. Pavese, A... "Experimental assessment of the seismic performance of a prefabricated concrete structural wall system", Engineering Structures.

\section{BIOGRAPHIES}

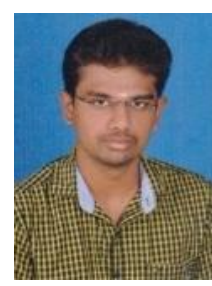

Post Graduate Student in KPR Institute of Engineering and Technology. Now I am doing My post graduate research work in CSIR-CECRI (Central Electro Chemical Research Institute), Karaikudi.

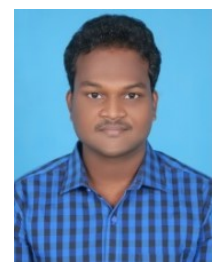

Post Graduate Student in Erode Builder Educational Trust's Group of Institutions. Now I am doing My Post Graduate research work in CSIR-CECRI (Central Electro Chemical Research Institute), Karaikudi.

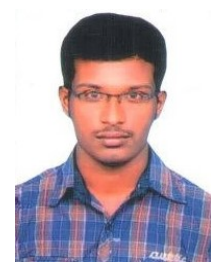

Post Graduate Student in PSNA college of Engineering and Technology. Now I am doing My Post Graduate research work in CSIR-CECRI (Central Electro Chemical Research Institute), Karaikudi.

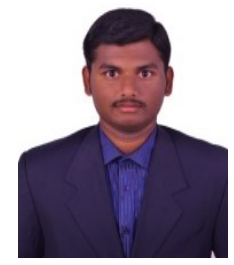

Post Graduate Student Sona college of Technology. Now I am doing My Post Graduate research work in CSIR-CECRI (Central Electro Chemical Research Institute), Karaikudi. 